\title{
Factors of the physical environment associated with walking and bicycling
}

Citation for published version (APA):

Wendel-Vos, G. C., Schuit, A. J., de Niet, R., Boshuizen, H. C., Saris, W. H., \& Kromhout, D. (2004). Factors of the physical environment associated with walking and bicycling. Medicine and Science in Sports and Exercise, 36(4), 725-730. https://doi.org/10.1249/01.MSS.0000121955.03461.0A

Document status and date:

Published: 01/01/2004

DOI:

10.1249/01.MSS.0000121955.03461.0A

Document Version:

Publisher's PDF, also known as Version of record

\section{Please check the document version of this publication:}

- A submitted manuscript is the version of the article upon submission and before peer-review. There can be important differences between the submitted version and the official published version of record.

People interested in the research are advised to contact the author for the final version of the publication, or visit the DOI to the publisher's website.

- The final author version and the galley proof are versions of the publication after peer review.

- The final published version features the final layout of the paper including the volume, issue and page numbers.

Link to publication

\footnotetext{
General rights rights.

- You may freely distribute the URL identifying the publication in the public portal. please follow below link for the End User Agreement:

www.umlib.nl/taverne-license

Take down policy

If you believe that this document breaches copyright please contact us at:

repository@maastrichtuniversity.nl

providing details and we will investigate your claim.
}

Copyright and moral rights for the publications made accessible in the public portal are retained by the authors and/or other copyright owners and it is a condition of accessing publications that users recognise and abide by the legal requirements associated with these

- Users may download and print one copy of any publication from the public portal for the purpose of private study or research.

- You may not further distribute the material or use it for any profit-making activity or commercial gain

If the publication is distributed under the terms of Article $25 \mathrm{fa}$ of the Dutch Copyright Act, indicated by the "Taverne" license above, 


\title{
Factors of the Physical Environment Associated with Walking and Bicycling
}

\author{
G. C. WANDA WENDEL-VOS ${ }^{1,2}$, A. JANTINE SCHUIT ${ }^{1}$, RAYMOND DE NIET ${ }^{1}$, HENDRIEK C. BOSHUIZEN ${ }^{1}$, \\ WIM H. M. SARIS ${ }^{3}$, and DAAN KROMHOUT ${ }^{1,2}$ \\ ${ }^{I}$ National Institute for Public Health and the Environment, Bilthoven, THE NETHERLANDS; ${ }^{2}$ Wageningen University, \\ Wageningen, THE NETHERLANDS; and ${ }^{3}$ Nutrition and Toxicology Research Institute (NUTRIM), Maastricht University, \\ Maastricht, THE NETHERLANDS
}

\begin{abstract}
WENDEL-VOS, G. C. W., A. J. SCHUIT, R. DE NIET, H. C. BOSHUIZEN, W. H. M. SARIS, and D. KROMHOUT. Factors of the Physical Environment Associated with Walking and Bicycling. Med. Sci. Sports Exerc., Vol. 36, No. 4, pp. 725-730, 2004. Purpose: The purpose of this study was to identify factors of the physical environment that may influence time spent on walking and bicycling. Methods: Demographic factors and time spent on walking and bicycling (during leisure time and for commuting purposes) were assessed with a self-administered questionnaire. GIS databases were used to objectively measure the total square area of green space and recreational space (woods, parks, sport grounds, allotments for vegetable gardens, and grounds for day trips) in a circle around the postal code of a respondent with a radius of 300 and $500 \mathrm{~m}$. Multilevel regression analysis was used to study the association between walking and bicycling on the one hand, and green and recreational space on the other hand. Analyses were adjusted for gender, age, and educational level. Results: In a neighborhood defined as a circle with a 300-m radius, the square area of sport grounds was associated with bicycling in general and the square area of parks was associated with bicycling for commuting purposes. It is, however, very likely that these results reflect the association of living in the outskirts of town and time spent on bicycling. Conclusion: The present study showed green and recreational space, specifically sport grounds and parks, to be associated with time spent on bicycling. Key Words: PHYSICAL ACTIVITY, GREEN SPACE, RECREATIONAL SPACE, MULTILEVEL REGRESSION, GIS
\end{abstract}

$\mathrm{P}$ hysical activity is one of the leading modifiable risk factors for various chronic diseases in Western countries (11). Extensive literature on the various health benefits of physical activity has lead to the need to understand the determinants of physical activity. Previous studies have described the association with physical activity for psychosocial determinants such as attitudes, social norms, and self-efficacy $(9,10,12,13)$. Another group of potential determinants of physical activity belongs to the physical environment. These factors are the least studied determinants of physical activity despite their ability to influence large populations.

Physical environments have the capacity to obstruct or to facilitate physical activity. For example, the presence of bicycle paths may make it easier and saver for people to be physically active, whereas the absence of such facilities or a high crime rate may pose as a barrier to physical activity. Recently, Humpel and coworkers (8) reviewed the findings

Address for correspondence: Wanda Wendel-Vos, National Institute for Public Health and the Environment, Centre for Prevention and Health Services Research, P.O. Box 1, 3720 BA Bilthoven, The Netherlands; E-mail: Wanda.Vos@rivm.nl.

Submitted for publication July 2003.

Accepted for publication November 2003

0195-9131/04/3604-0725

MEDICINE \& SCIENCE IN SPORTS \& EXERCISE E

Copyright (C) 2004 by the American College of Sports Medicine

DOI: $10.1249 / 01 . M S S .0000121955 .03461 .0 \mathrm{~A}$ of 19 quantitative studies addressing the association of particular environmental attributes with physical activity. In only four of these studies objective measures of the environment were used. The methods used varied from place of residence using postal codes, until physical distance to, and accessibility of facilities. Because only a small subset of possible physical environmental characteristics has been studied and because the use of objective measures of the physical environment is clearly staying behind compared to the use of self-reported measures, further research in this field is needed.

In the present study, we made an effort to identify factors of the physical environment that may influence walking and bicycling during leisure time and for commuting purposes. In order to do so, time spent on walking and bicycling in these domains of physical activity were associated with the amount of green and recreational space within a radius of 300 and $500 \mathrm{~m}$ of the homes of the participants as documented in GIS databases.

\section{METHODS}

The data used in this study was collected at two levels. The individual level included a self-administered questionnaire on demographic factors and physical activity. The neighborhood-level included information on green space and recreational space derived from GIS databases. These two levels were connected by the postal code, creating a multilevel design for data analyses since one postal code corresponded to more than one individual. 
Data collection at the individual level. Respondents of this study were living in and around Maastricht, a medium-sized town in the southern part of The Netherlands. All these people were former participants of two monitoring studies of the National Institute for Public Health and the Environment conducted in the periods 1987-92 and 1993-7 $(17,19)$. Each of these years, a random sample of men and women aged 20-59 yr was selected from the municipal registry. The measurement included a physical examination at the Municipal Health Service and a self-administered questionnaire that was checked for errors at the Health Centre in the presence of the participant. Respectively, the Medical Ethical Committee of the University of Leiden and the external Medical-Ethical Committee of the TNO Toxicology and Nutrition Institute approved these former studies. In 1998, 19,857 people were invited to participate in a mailed survey. In total, 13,184 people (66.4\%) completed the 1998 questionnaire. All participants signed a consent form allowing us to use the information from this questionnaire for scientific purposes.

Demographic factors in the self-administered questionnaire included gender and age. Data on educational level was not available within this measurement. However, assuming that this attribute does not substantially change over time among adults, information on educational level was derived from the former measurement of these participants. Educational level was classified into three categories: low (lower vocational training or primary school), medium (secondary school and intermediate vocational training), and high (higher vocational training or university). The assessment of health status included questions about perceived health status (five-point scale ranging from excellent till poor), height, and weight (both self-reported). Physical activity was administered using the short questionnaire to assess health enhancing physical activity (in short: SQUASH). This questionnaire includes questions (frequency, duration, and intensity) on four domains of physical activity, e.g., commuting activities (walking and bicycling), occupational physical activity, household activity, and leisure-time physical activity (walking, bicycling, gardening, doing odd jobs, and sports). In a previous study, the SQUASH was validated with a CSA activity monitor in a population of 36 men and 14 women, aged 27-58 (20). The correlation coefficient for validity was 0.45 (95\% CI 0.17 $0.66)$. Reproducibility of the separate questions ranged from 0.44 to $0.96(20)$.

In the present study, we assumed that the physical environment of the home would be mostly related to activities that are conducted directly from the home, such as walking and bicycling. The physical activity questionnaire used provided data on walking and bicycling during leisure time as well as for commuting purposes. Therefore, we addressed our research question for walking and bicycling in both of these domains separately as well as in both domains combined.

Data collection at the neighborhood level. The Maastricht region is the hilliest region of The Netherlands but does not include mountains. The largest areas of green and recreational space that could be used for walking and bicycling during leisure time are situated in the outskirts of the city as well as outside the city. Destinations for walking and bicycling for commuting purposes (e.g., companies) are scattered around town. The two railroad stations of Maastricht are situated away from the city center. One is situated at walking distance (15 $\mathrm{min}$ ) of the city center, and one is situated in the outskirts.

Data on the physical environment were derived from existing GIS databases of Statistics Netherlands on land utilization including the amount of green space and recreational space. Green and recreational space included woods, parks, sport grounds, allotments where people grow vegetables for personal use, and grounds used for day trips such as the zoo and amusement parks. Sport grounds included things like soccer fields and tennis courts but not gymnasiums and fitness centers.

The databases were coded at the level of postal codes with maximal precision (e.g., six positions). In the GIS-databases an $\mathrm{x}, \mathrm{y}$-coordinate represents these postal codes, most of the time representing one street or one side of a street. On average, a six-position postal code in the Netherlands represents 16.2 households. Among the postal codes used in the present study, a postal code represented an average of 20.9 households.

Two "neighborhoods" around the six position postal codes were defined; one with a radius of $300 \mathrm{~m}$ and one with a radius of $500 \mathrm{~m}$. These two radiuses were thought to be applicable for activities conducted directly from the home such as walking and bicycling. Moreover, the 500-m radius is included in the quality characteristics (e.g., more recreational space within $500 \mathrm{~m}$ of the home represents a higher quality of the recreational environment) for recreation close to the home as raised by the Dutch recreational counsel.

For every neighborhood, the square meters of woods, parks, sport grounds, allotments, and day-trip grounds within the 300- and 500-m radius neighborhood were calculated in the GIS database. Then, these results were transferred to a flat data file and merged with the individual data. Consequently, the data set used for statistical analyses had a multilevel structure. Every individual was linked to a neighborhood through his/her postal code and every postal code was linked to an amount of square meters of green or recreational space.

Data analysis. Respondents with missing data on age, educational level, walking, and bicycling $(N=641)$ were excluded from the analyses. In addition, respondents who had moved out of the Maastricht area $(N=1002)$ were excluded. Consequently, complete data was available for 11,541 respondents. In this data set, the amount of individuals per postal code ranged from 1 to 30 with a median value of five individuals per postal code.

Multilevel regression analyses were used to study the association between physical activity (dependent variable) and physical environment variables (independent variables). This method is appropriate, because the data structure was hierarchical with physical environments including more than one participant. The mixed procedure within the sta- 
TABLE 1. Characteristics (mean (SD) or \%) of the study population stratified by gender.

\begin{tabular}{|c|c|c|}
\hline & $\operatorname{Men}(N=5353)$ & Women $(N=6188)$ \\
\hline Age (yr) & $49.6(10.5)$ & $48.7(10.9)$ \\
\hline \multicolumn{3}{|l|}{ Educational level (\%) } \\
\hline Low & 52.2 & 63.4 \\
\hline Medium & 24.7 & 20.2 \\
\hline High & 23.1 & 16.4 \\
\hline \multicolumn{3}{|c|}{ Perceived health status (\%) } \\
\hline Excellent/very good & 26.6 & 22.9 \\
\hline Good & 60.2 & 61.4 \\
\hline Mediocre/poor & 13.2 & 15.7 \\
\hline \multicolumn{3}{|l|}{ Body mass index (\%) } \\
\hline$<25 \mathrm{~kg} \cdot \mathrm{m}^{-2}$ & 45.8 & 62.7 \\
\hline $25-30 \mathrm{~kg} \cdot \mathrm{m}^{-2}$ & 44.4 & 28.0 \\
\hline$\geq 30 \mathrm{~kg} \cdot \mathrm{m}^{-2}$ & 9.8 & 9.3 \\
\hline \multicolumn{3}{|l|}{ Physical activity } \\
\hline Walking $\left(h \cdot w^{-1}\right)$ & $2.8(4.7)$ & $2.5(3.6)$ \\
\hline Bicycling $\left(h \cdot w^{-1}\right)$ & $1.5(3.6)$ & $1.3(2.8)$ \\
\hline
\end{tabular}

tistical package SAS (version 8.2) was used to carry out multilevel regression analysis using random intercept models, restricted maximum likelihood estimation, and an unstructured covariance structure. The intercept of these models is interpreted as the average amount of physical activity if the physical environment variable would be equal to zero. The slope of these models is interpreted as the average change in physical activity caused by a one-unit change in the physical environment variable. Multivariate analyses included age, educational level, and gender.

\section{RESULTS}

Table 1 shows the characteristics of the study population. The study population consisted of 5353 men $(46 \%)$ and 6188 women (54\%). The mean age of the study population was $49 \mathrm{yr}$ and the majority of the participants had a low educational level. Women more often than men reported a body mass index below $25 \mathrm{~kg} \cdot \mathrm{m}^{-2}$, whereas a body mass index between 25 and $30 \mathrm{~kg} \cdot \mathrm{m}^{-2}$ was more prevalent among men. In general, men tended to be more active than women (Table 1). The distribution of the amount of green space and recreational space in the neighborhood is described in Table 2. Parks and sport grounds were more common among the neighborhoods in our study than woods, allotments, and day-trip grounds.

Table 3 shows the results of the multilevel regression analyses between walking and bicycling for leisure-time and physical environmental variables. Table 4 and 5 show the results for walking and bicycling for commuting purposes and total time spent on walking and bicycling respectively. On average, the between person variance was approximately 100 times greater than the between postal code variance (data not shown). No associations were found for attributes of green and recreational space and walking. In the neighborhoods with a 500-m radius, crude analyses did show a significant association between time spent on walking and the square area of sport grounds. However, this association was no longer present when adjustments were made for gender, age, and educational level. The association with the square area of sport grounds in neighborhoods with a 300-m radius was consistently present for leisure time $(\beta=0.04$; Table 3$)$, commuting purposes $(\beta=0.02$; Table 4$)$, as well as total time spent on walking and bicycling $(\beta=0.06$; Table 5) and was independent of gender, age, and educational level. For bicycling during leisure time, this association was also present in neighborhoods with a 500-m radius. However, this association was not independent of gender, age, and educational level. Only in neighborhoods with a $300-\mathrm{m}$ radius was the square area of parks associated with bicycling for commuting purposes $(\beta=0.02$; Table 4$)$ independent of gender, age, and educational level.

\section{DISCUSSION}

In this study, physical environmental factors associated with walking and bicycling were investigated. In a neighborhood defined as a circle with a 300-m radius around the postal codes of the participants, time spent on bicycling was associated with the square area of sport grounds in that neighborhood independent of gender, age, educational level, and domain of physical activity. Bicycling for commuting purposes was associated, independent of gender, age, and educational level, with the square area of parks in neighborhoods with a $300-\mathrm{m}$ radius.

In general, using GIS databases to study physical environmental factors in relation to physical activity has some distinct advantages compared with relying on only the perception of the physical environment. First, these databases give an objective measure of, for example, the amount of green areas, recreational facilities, and sports facilities in the neighborhood, which makes it easier to compare neighborhoods across towns. Second, the use of existing information

TABLE 2. Distribution of the amount (in hectares (ha)) of green space and recreational space in the neighborhood.

\begin{tabular}{|c|c|c|c|c|c|c|c|}
\hline & Minimum & $\begin{array}{c}\text { 50th } \\
\text { Percentile }\end{array}$ & $\begin{array}{c}\text { 75th } \\
\text { Percentile }\end{array}$ & $\begin{array}{c}\text { 90th } \\
\text { Percentile }\end{array}$ & $\begin{array}{c}\text { 95th } \\
\text { Percentile }\end{array}$ & $\begin{array}{c}\text { 99th } \\
\text { Percentile }\end{array}$ & Maximum \\
\hline \multicolumn{8}{|c|}{ Neighborhoods with a $300-m$ radius } \\
\hline Woods & 0.0 & 0.0 & 0.0 & 0.0 & 0.3 & 3.0 & 12.0 \\
\hline Parks & 0.0 & 0.0 & 0.4 & 2.9 & 4.4 & 7.2 & 10.7 \\
\hline Sport grounds & 0.0 & 0.0 & 1.1 & 3.2 & 4.6 & 8.7 & 12.6 \\
\hline Allotments & 0.0 & 0.0 & 0.0 & 0.0 & 0.4 & 1.6 & 4.6 \\
\hline Day-trip grounds & 0.0 & 0.0 & 0.0 & 0.0 & 0.0 & 4.0 & 17.9 \\
\hline \multicolumn{8}{|c|}{ Neighborhoods with a $500-m$ radius } \\
\hline Woods & 0.0 & 0.0 & 0.0 & 1.4 & 4.2 & 9.2 & 35.0 \\
\hline Parks & 0.0 & 0.2 & 3.1 & 6.2 & 9.7 & 17.6 & 21.5 \\
\hline Sport grounds & 0.0 & 1.5 & 4.5 & 7.9 & 11.2 & 20.9 & 32.2 \\
\hline Allotments & 0.0 & 0.0 & 0.0 & 0.9 & 1.6 & 3.7 & 4.6 \\
\hline Day-trip grounds & 0.0 & 0.0 & 0.0 & 0.0 & 2.4 & 11.8 & 34.4 \\
\hline
\end{tabular}




\begin{tabular}{|c|c|c|c|c|c|c|c|c|}
\hline & \multicolumn{4}{|c|}{ Neighborhoods with a $300-\mathrm{m}$ radius } & \multicolumn{4}{|c|}{ Neighborhoods with a $500-\mathrm{m}$ radius } \\
\hline & \multicolumn{2}{|c|}{ Crude Analyses } & \multicolumn{2}{|c|}{$\begin{array}{l}\text { Adjusted for Age, Gender, } \\
\text { and Educational Level }\end{array}$} & \multicolumn{2}{|c|}{ Crude Analyses } & \multicolumn{2}{|c|}{$\begin{array}{l}\text { Adjusted for Age, Gender, } \\
\text { and Educational Level }\end{array}$} \\
\hline & Beta\# & $95 \% \mathrm{Cl}$ & Beta $^{\#}$ & $95 \% \mathrm{Cl}$ & Beta" & $95 \% \mathrm{Cl}$ & Beta\# $^{\#}$ & $95 \% \mathrm{Cl}$ \\
\hline \multicolumn{9}{|l|}{ Walking $\left(h \cdot w^{-1}\right)$} \\
\hline Woods (ha) & 0.06 & $(-0.06,0.18)$ & 0.08 & $(-0.03,0.20)$ & 0.00 & $(-0.04,0.04)$ & 0.01 & $(-0.03,0.04)$ \\
\hline Parks (ha) & 0.03 & $(-0.02,0.08)$ & 0.02 & $(-0.03,0.07)$ & 0.01 & $(-0.01,0.03)$ & 0.00 & $(-0.02,0.02)$ \\
\hline Sport grounds (ha) & 0.03 & $(-0.02,0.07)$ & 0.02 & $(-0.03,0.06)$ & $0.02^{*}$ & $(0.01,0.04)$ & 0.01 & $(-0.01,0.03)$ \\
\hline Allotments (ha) & 0.10 & $(-0.14,0.34)$ & 0.09 & $(-0.14,0.33)$ & -0.01 & $(-0.13,0.10)$ & -0.02 & $(-0.13,0.10)$ \\
\hline Day-trip grounds (ha) & -0.06 & $(-0.17,0.05)$ & -0.07 & $(-0.18,0.04)$ & 0.01 & $(-0.03,0.04)$ & 0.00 & $(-0.03,0.04)$ \\
\hline \multicolumn{9}{|l|}{ Bicycling $\left(h \cdot w^{-1}\right)$} \\
\hline Woods (ha) & 0.01 & $(-0.08,0.10)$ & 0.02 & $(-0.07,0.11)$ & 0.02 & $(-0.01,0.05)$ & 0.02 & $(-0.01,0.05)$ \\
\hline Parks (ha) & 0.02 & $(-0.02,0.06)$ & 0.01 & $(-0.03,0.05)$ & 0.01 & $(-0.01,0.03)$ & 0.00 & $(-0.01,0.02)$ \\
\hline Sport grounds (ha) & $0.04^{*}$ & $(0.01,0.08)$ & $0.04^{*}$ & $(0.01,0.07)$ & $0.02^{*}$ & $(0.01,0.03)$ & 0.01 & $(0.00,0.03)$ \\
\hline Allotments (ha) & -0.04 & $(-0.22,0.14)$ & -0.04 & $(-0.22,0.13)$ & 0.04 & $(-0.04,0.13)$ & 0.04 & $(-0.05,0.13)$ \\
\hline Day-trip grounds (ha) & 0.04 & $(-0.04,0.13)$ & 0.04 & $(-0.04,0.12)$ & 0.02 & $(-0.01,0.05)$ & 0.02 & $(-0.01,0.05)$ \\
\hline
\end{tabular}

* $P<0.05$.

\# Beta represents the number of hours per week of extra activity corresponding with an increase of one hectare in the particular environmental factor.

is cost saving for the study. Therefore, geographic databases seem to be a promising source of information in order to study the association between physical activity and physical environmental factors.

A disadvantage of GIS databases is that they are not sufficient to fully describe the association under study. To do this, objectively measured factors of the physical environment (such as features of GIS databases) will have to be combined with measurement of safety aspects as well as measurement of the perception that people have of their physical environment. In our analyses, we did not take these aspects into account because such data were not available to us at the time of this study. Modest to high crime rates and the lack of safe bicycle paths and sidewalks may, however, very likely pose as a barrier to physical activity in the sense that people take the car to work or the shopping center instead of going by bike or walk to these places. It is also very likely that even when in theory a physical environment invites people to take a walk in the neighborhood, they hesitate to do so because of the safety aspects.

Several methodological aspects of the present study need to be addressed. First, the Maastricht region did not include a wide range of types of green and recreational space. Only parks and sport grounds were reasonably represented. Therefore, we were unlikely to find associations for other types of green and recreational space. In addition, the between person variance was much larger than the between postal code variance, indicating a high degree of independence between individuals and postal codes and therefore indicating an increased power to find statistically significant results. However, this was not reflected in the associations found between physical activity and green and recreational space. This was probably due to the very small effects we were looking for, which would need a larger population in order to find statistically significant results. Also, the information in the GIS databases was probably aggregated to a higher level than needed for our purpose. For example, the item "parks" included not only the parks but also center strips between roads and other green belts in the city irrespective of their sizes. Although green strips between road lanes do contribute to the esthetics of green spaces, these features are unlikely to be a destination for physical activity. For the purpose of linking the average level of physical activity to these kinds of aspects of the neighborhood, less aggregated (e.g., separate data on center strips and parks) information will probably be more appropriate. Therefore, to fully examine the possibilities of geographical databases to study physical environmental factors associated with physical activity our analyses should be repeated with the use of databases that are less aggregated. These databases

TABLE 4. Associations between walking and bicycling for commuting purposes and square area of green and recreational space.

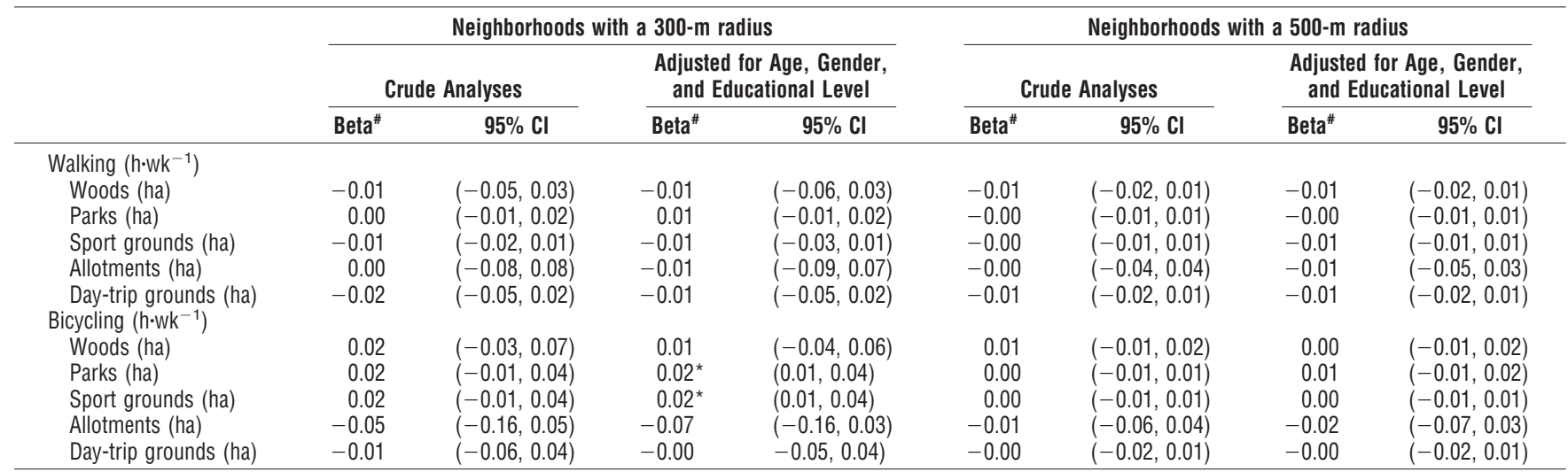

* $P<0.05$

\# Beta represents the number of hours per week of extra activity corresponding with an increase of one hectare in the particular environmental factor. 
TABLE 5. Associations between walking and bicycling in leisure time and for commuting purposes combined and square area of green and recreational space.

\begin{tabular}{|c|c|c|c|c|c|c|c|c|}
\hline & \multicolumn{4}{|c|}{ Neighborhoods with a $300-\mathrm{m}$ radius } & \multicolumn{4}{|c|}{ Neighborhoods with a $500-\mathrm{m}$ radius } \\
\hline & \multicolumn{2}{|c|}{ Crude Analyses } & \multicolumn{2}{|c|}{$\begin{array}{l}\text { Adjusted for Age, Gender, } \\
\text { and Educational Level }\end{array}$} & \multicolumn{2}{|c|}{ Crude Analyses } & \multicolumn{2}{|c|}{$\begin{array}{l}\text { Adjusted for Age, Gender, } \\
\text { and Educational Level }\end{array}$} \\
\hline & Beta\# $^{\#}$ & $95 \% \mathrm{Cl}$ & Beta\# & $95 \% \mathrm{Cl}$ & Beta" & $95 \% \mathrm{Cl}$ & Beta\# & $95 \% \mathrm{Cl}$ \\
\hline \multicolumn{9}{|l|}{ Walking $\left(h \cdot w^{-1}\right)$} \\
\hline Woods (ha) & 0.05 & $(-0.08,0.18)$ & 0.07 & $(-0.06,0.20)$ & -0.01 & $(-0.05,0.03)$ & -0.00 & $(-0.04,0.04)$ \\
\hline Parks (ha) & 0.03 & $(-0.02,0.09)$ & 0.02 & $(-0.03,0.08)$ & 0.01 & $(-0.02,0.03)$ & -0.00 & $(-0.03,0.02)$ \\
\hline Sport grounds (ha) & 0.02 & $(-0.03,0.07)$ & 0.01 & $(-0.04,0.06)$ & 0.01 & $(-0.01,0.03)$ & 0.01 & $(-0.01,0.03)$ \\
\hline Allotments (ha) & 0.11 & $(-0.15,0.36)$ & 0.09 & $(-0.16,0.34)$ & -0.02 & $(-0.14,0.11)$ & -0.03 & $(-0.15,0.09)$ \\
\hline Day-trip grounds (ha) & -0.07 & $(-0.19,0.05)$ & -0.08 & $(-0.20,0.04)$ & -0.00 & $(-0.04,0.04)$ & -0.01 & $(-0.04,0.04)$ \\
\hline \multicolumn{9}{|l|}{ Bicycling $\left(h \cdot w k^{-1}\right)$} \\
\hline Woods (ha) & 0.03 & $(-0.08,0.15)$ & 0.03 & $(-0.09,0.14)$ & 0.02 & $(-0.01,0.06)$ & 0.02 & $(-0.01,0.06)$ \\
\hline Parks (ha) & 0.04 & $(-0.01,0.08)$ & 0.03 & $(-0.01,0.08)$ & 0.01 & $(-0.01,0.03)$ & 0.01 & $(-0.01,0.03)$ \\
\hline Sport grounds (ha) & $0.06^{*}$ & $(0.02,0.10)$ & $0.06^{\star}$ & $(0.01,0.10)$ & 0.02 & $(-0.00,0.03)$ & 0.01 & $(-0.00,0.03)$ \\
\hline Allotments (ha) & -0.09 & $(-0.31,0.13)$ & -0.11 & $(-0.33,0.11)$ & 0.03 & $(-0.08,0.14)$ & 0.02 & $(-0.09,0.13)$ \\
\hline Day-trip grounds (ha) & 0.03 & $(-0.07,0.14)$ & 0.04 & $(-0.07,0.14)$ & 0.02 & $(-0.02,0.05)$ & 0.02 & $(-0.02,0.05)$ \\
\hline
\end{tabular}

* $P<0.05$.

\# Beta represents the number of hours per week of extra activity corresponding with an increase of one hectare in the particular environmental factor.

should probably target specific environmental aspect of interest, for example the amount of bicycle paths, the amount of parks in the neighborhood and the distance to facilities, such as health clubs, schools, and shopping centers in the neighborhood. In case of a study on the distance to facilities in relation to the use of these facilities and/or how people transport themselves (e.g., car, bicycle, or walking) to these facilities it would be of great importance to include the presence of physical barriers (e.g., ring way, railroad, rivers, and canals). In other words, aspects of the physical environment that are possibly linked to physical activity are diverse, and together they constitute a complex model that is difficult to grasp within one study.

Studies that used self-reported environmental factors to study the association between physical activity and the physical environment generally found access to recreational facilities, neighborhood safety, and enjoyable scenery to be related to physical activity levels and/or physical activity participation (1,3-6,10,14-16). Only few studies addressed objective measures of the physical environment. Bauman et al. investigated the relationship between proximity to the coast and physical activity among a stratified sample of adults from households in New South Wales. Participants were classified as either "coastal" or "inland" based on their postal code of residence. Living near the coast was found to be associated with higher levels of physical activity independently from sex, age, country of birth, level of education, and employment status (2). Sallis et al. (15) studied the association between the frequency of exercise and the distance between homes and exercise facilities among a random sample of adults living in San Diego. The distance between homes and exercise facilities was calculated using a street map of San Diego that included the geographical co-ordinates of both the homes of the participants and the exercise facilities. Density of exercise facilities around one's house was found to be associated with exercise habits independent of demographic variables such as age, education, and income.

The Study on Environmental and Individual Determinants of physical activity (the SEID project) showed that recreational facilities located near home were used more often than facilities located elsewhere among healthy workers and homemakers in Western Australia. The distances between the homes and exercise facilities were calculated using data derived from GIS databases. Most frequently used facilities were the streets (by $45.6 \%$ of the respondents), public open space (28.8\%), and the beach $(22.7 \%)$. It was concluded from this study that accessible facilities determined whether or not they were used and, in this way, support and enhance physical activity by providing opportunities (7). Troped et al. (18) studied the association between self-reported and objective physical environment factors and use of a community rail-trail among a random sample of adults living in Arlington, MA. Three objective environmental variables were defined based on GIS databases: distance to the bikeway, steep-hill barrier, and a busy street barrier. The steep-hill barrier and greater distance to the bikeway were associated with nonuse of the bikeway.

In the present study, inhabitants of the Dutch town Maastricht living in a neighborhood with a larger square area of sport grounds close to home spent more time on bicycling in general. Individuals living in a neighborhood with a larger square area of parks close to home spent more time on bicycling for commuting purposes. GIS data of the present study showed that the largest amounts of sport grounds as well as parks were mostly situated at the outskirts of the town. Therefore, it is likely that our results are a reflection of the results that we would have found if the aim of the study would have been to study the association between the location of the home (e.g., center vs outskirts) and time spent on walking and bicycling. Concerning leisure-time bicycling, a possible explanation could be that people living in neighborhoods with a larger square area of sport grounds (e.g., people living in the outskirts of town) spent more time on bicycling because for them it is relatively easy to reach nonurban surroundings that are more attractive for bicycling than it is for people living in the center parts of town. Theoretically, it would be possible that these people use their bikes for transportation to the sport grounds. However, the square area of sport grounds would have to be associated with time spent on sports and secondary analyses showed that this was not the case. Concerning bicycling for com- 
muting purposes, a possible explanation could be that people living in neighborhoods with a larger square area of sport grounds and/or parks (e.g., people living in the outskirts of town) also live close to one of the railway stations and therefore are more likely to use their bicycle for commuting purposes.

Despite of the adjustments made for educational level, it is possible that the associations found are influenced to some degree by the social economic status of the participants. Housing types in Dutch neighborhoods are quite uniform, meaning that its inhabitants will have a more or

\section{REFERENCES}

1. Ball, K., A. Bauman, E. Leslie, and N. Owen. Perceived environmental aesthetics and convenience and company are associated with walking for exercise among Australian adults. Prev. Med. 33:434-440, 2001.

2. Bauman, A., B. Smith, L. Stoker, B. Bellew, and M. Boоth. Geographical influences upon physical activity participation: evidence of a "coastal effect." Aust. N. Z. J. Public Health 23:322324, 1999.

3. Boотh, S. L., J. F. Sallis, C. Ritenbaugh, et al. Environmental and societal factors affect food choice and physical activity: rationale, influences, and leverage points. Nutr. Rev. 59:S21-S39; discussion S57-S65, 2001.

4. Clark, D. O. Physical activity and its correlates among urban primary care patients aged 55 years or older. J. Gerontol. B Psychol. Sci. Soc. Sci. 54:S41-S48, 1999.

5. Eyler, A. A., E. Baker, L. Cromer, A. C. King, R. C. Brownson, and R. J. Donatelle. Physical activity and minority women: a qualitative study. Health Educ. Behav. 25:640-652, 1998.

6. French, S. A., M. Story, and R. W. JefFery. Environmental influences on eating and physical activity. Annu. Rev. Public Health 22:309-335, 2001.

7. Giles-Corti, B., and R. J. Donovan. The relative influence of individual, social and physical environment determinants of physical activity. Soc. Sci. Med. 54:1793-1812, 2002.

8. Humpel, N., N. Owen, and E. LesLie. Environmental factors associated with adults' participation in physical activity: a review. Am. J. Prev. Med. 22:188-199, 2002.

9. KING, A. C. Community and public health approaches to the promotion of physical activity. Med. Sci. Sports Exerc. 26:14051412, 1994.

10. King, A. C., C. Castro, S. Wilcox, A. A. Eyler, J. F. Sallis, and R. C. BRownson. Personal and environmental factors associated with physical inactivity among different racial-ethnic groups of U. S. middle-aged and older-aged women. Health Psychol. 19: 354-364, 2000.

11. Mathers, C. D., E. T. Vos, C. E. Stevenson, and S. J. Begg. The Australian Burden of Disease Study: measuring the loss of health less comparable social economic status. This means that we probably could not fully adjust for this factor in our analyses. In other words, the present study showed that living in a neighborhood with sport grounds and or parks close to home is associated with time spent on bicycling. It is, however, very likely that these results reflect the association of living in the outskirts of town and time spent on bicycling. Moreover, this study showed that more research is necessary to fully examine the possibilities of geographical databases to study physical environmental factors associated with physical activity.

from diseases, injuries and risk factors. Med. J. Aust. 172:592596, 2000.

12. Nies, M. A., M. Vollman, and T. Cook. Facilitators, barriers, and strategies for exercise in European American women in the community. Public Health Nurs. 15:263-272, 1998.

13. NToumanis, N., and S. J. BiddLE. A review of motivational climate in physical activity. J. Sports Sci. 17:643-665, 1999.

14. Rutten, A., T. Abel, L. Kannas, et al. Self reported physical activity, public health, and perceived environment: results from a comparative European study. J. Epidemiol. Community Health 55:139-146, 2001.

15. Sallis, J. F., M. F. Hovell, C. R. Hofstetter, et al. Distance between homes and exercise facilities related to frequency of exercise among San Diego residents. Public Health Rep. 105:179$185,1990$.

16. Sallis, J. F., M. F. Johnson, K. J. Calfas, S. Caparosa, and J. F. Nichols. Assessing perceived physical environmental variables that may influence physical activity. Res. Q. Exerc. Sport 68:345351, 1997.

17. Smit, H. A., W. M. M. Verschuren, H. B. Bueno de Mesquita, et al. The Monitoring project on risk factors for chronic diseases in the Netherlands (MORGEN-project): aim and method. Bilthoven: National Institute for Public Health and the Environment; report number 263200001 [In Dutch]; 1994.

18. Troped, P. J., R. P. Saunders, R. R. Pate, B. Reininger, J. R. Ureda, and S. J. Thompson. Associations between self-reported and objective physical environmental factors and use of a community rail-trail. Prev. Med. 32:191-200, 2001.

19. Verschuren, W. M. M., E. van Leer, A. Blokstra, et al. Cardiovascular disease risk factors in The Netherlands. Neth. J. Cardiol. 4:205-210, 1993.

20. Wendel-Vos, G., A. Schuit, W. Saris, and D. Kromhout. Reproducibility and relative validity of the short questionnaire to assess health enhancing physical activity. J. Clin. Epidemiol. 56:1163$1169,2003$. 